\title{
Effectiveness of Sentinel-1-2 Multi-Temporal Composite Images for Land-Cover Monitoring in the Indochinese Peninsula
}

\author{
Nguyen Thanh Hoan',2, Ram C. Sharma3 , Nguyen Van Dung1, Dang Xuan Tung4 \\ ${ }^{1}$ Institute of Geography, Vietnam Academy of Science and Technology, Hanoi, Vietnam \\ ${ }^{2}$ Graduate University of Science and Technology, Vietnam Academy of Science and Technology, Hanoi, Vietnam \\ ${ }^{3}$ Department of Informatics, Tokyo University of Information Sciences, Chiba, Japan \\ ${ }^{4}$ Institute of Geological Sciences, Vietnam Academy of Science and Technology, Hanoi, Vietnam \\ Email: hoanrs@gmail.com,nthoan@ig.vast.vn
}

How to cite this paper: Hoan, N. T., Sharma, R. C., Van Dung, N., \& Tung, D. X. (2020). Effectiveness of Sentinel-1-2 Multi-Temporal Composite Images for Land-Cover Monitoring in the Indochinese Peninsula. Journal of Geoscience and Environment Protection, 8, 24-32.

https://doi.org/10.4236/gep.2020.89002

\section{Received: July 20, 2020}

Accepted: September 5, 2020

Published: September 8, 2020

Copyright $\odot 2020$ by author(s) and Scientific Research Publishing Inc. This work is licensed under the Creative Commons Attribution International License (CC BY 4.0).

http://creativecommons.org/licenses/by/4.0/

(c) (i) Open Access

\begin{abstract}
The Indochinese Peninsula, which contains two thirds of the world's tropical forests, however, is one of the world's most threatened habitat with some of the highest rates of deforestation and land use changes. Availability of higher resolution satellite data collected by the likes of Landsat 8 and Sentinel-1-2 has brought new opportunities for precise land cover monitoring in recent years. However, utilizing a massive volume of high spatial and temporal resolution data for ecological applications is challenging. One approach is to employ composite images generated from the multi-temporal satellite data. The research was conducted in two study sites located in the Indochinese Peninsula, Laos-Thailand and Vietnam-Cambodia, vulnerable to deforestation and land use changes. We assessed the potential of recently available composite images, such as Biophysical Image Composite (BIC), Forest Cover Composite (FCC), Enhanced Forest Cover Composite (EFCC), and Water Cover Composite (WCC) for the classification and mapping of land cover types. Three machine learning classifiers, k-Nearest Neighbors (KNN), Support Vector Machines (SVM) and Random Forests (RF) were employed and the performance of composite images was evaluated quantitatively with the support of ground truth data. The overall accuracies (Kappa coefficient) obtained from the combination of composite images were $0.92(0.89)$ and $0.90(0.86)$ for Laos-Thailand, and Vietnam sites respectively. These results highlight effectiveness of the composite images for the classification and mapping of land cover types.
\end{abstract}

\section{Keywords}

Satellite, Remote Sensing, Machine Learning, Optical, Radar 


\section{Introduction}

The Indochinese Peninsula, usually referred to as the mainland of Southeast Asia, consists of the countries of Myanmar, Thailand, peninsular Malaysia, Laos, Cambodia and Vietnam (Keyes, 1994). This region is mostly drained by the river systems in a north-south direction from the Tibetan Plateau.

The Indochinese Peninsula is one of the world's top biodiversity hotspots (de Bruyn et al., 2014). It also contains two thirds of the world's tropical forests; however, it is one of the world's most threatened habitats with some of the highest rates of deforestation (Stibig et al., 2014; Keenan et al., 2015). The deforestation has affected the regional monsoon and climate (Kanae et al., 2001; Sen et al., 2004) and agricultural productivity (Lawrence \& Vandecar, 2015) as well. The construction of large dams in the rivers also has impacts on wetlands and migratory birds, freshwater biodiversity, and rural livelihood (Dudgeon, 2000).

Satellite remote sensing can be a suitable technology for timely monitoring of rapidly changing environment and can play a key role to protect unique biodiversity of the region (Wang et al., 2010; Miettinen et al., 2014; Mulatu et al., 2017). The multi-spectral, high-resolution satellite imagery has been recognized as the potential technology to greatly facilitate conservation, management, and decision-making (Kerr \& Ostrovsky, 2003; Boyle et al., 2014; Hoan et al., 2013).

Availability of higher resolution satellite data collected by the likes of Landsat 8 and Sentinel-1-2 has brought new opportunity for precise land cover monitoring in recent years (Malenovský et al., 2012; Roy et al., 2014; Herold et al., 2016; Hoan et al., 2018). However, utilizing a massive volume of high spatial and temporal resolution data for ecological applications is challenging. One approach is to employ composite images generated from the multi-temporal satellite data. The composite images are designed by conceptualizing the spectral characteristics and temporal/phenological variations of the land cover types by harnessing multi-temporal satellite images of an entire year (Sharma et al., 2019).

In previous study, Sharma et al. (2016) have already designed Biophysical Image Composite (BIC) for the visualization and extraction of major biophysical components, barren/urban, vegetation, and snow/water areas, on the surface of Earth. For the separate extraction and visualization of forest canopy, a new image composite called Forest Cover Composite (FCC) was designed in previous research (Sharma et al., 2018). For enhanced extraction and visualization of the forested areas, the annual median backscattering intensity of the $\mathrm{VH}$ (Vertical-transmit horizontal-receive) polarization values $\left(\mathrm{VH}_{\text {median }}\right)$ obtained from Sentinel-1 mission was combined with the green term of the FCC (NDVI $\left.{ }_{\text {mean }}\right)$ and Enhanced FCC (EFCC) was proposed (Sharma et al., 2018). Water Cover Composite (WCC), made up of annual minimum green $\left(\right.$ Green $\left._{\min }\right)$ reflectance, annual minimum near infrared $\left(\mathrm{Nir}_{\min }\right)$ reflectance, and annual maximum Superfine Water Index $\left(\mathrm{SWI}_{\max }\right)$ values as the red $(\mathrm{R})$, green $(\mathrm{G})$, and blue $(\mathrm{B})$ bands respectively, was designed for better extraction of surface water bodies in pre- 
vious study (Sharma et al., 2015; Sharma et al., 2019).

Importance of assessing the applicability of composite images in different geographical zones for the classification of land cover types has been emphasized (Sharma et al., 2019). In this study, the four Multi-Temporal Composite Images (BIC, FCC, EFCC, and WCC) were utilized to obtain land cover information for some different geographical zones of the Indochinese Peninsula. The general objective of the research is to enhance the ability of satellite remote sensing for land cover monitoring of the Indochinese Peninsula. The specific objectives of the research are as follows:

1) Evaluate the potential of recently available composite images (BIC, FCC, EFCC, and WCC) for the classification and mapping of major land cover types such as forest, grass, crop, and non-vegetation.

2) Assess the performance of different machine learning classifiers such as k-Nearest Neighbours (KNN), Support Vector Machines (SVM) and Random Forests (RF) for classification.

3) Produce land cover maps for the study sites using best-performed classifier and composite images at $10 \mathrm{~m}$ spatial resolution.

\section{Materials and Methods}

\subsection{Study Areas}

The research was conducted in two study sites, Laos-Thailand and Vietnam, located in the Indochinese Peninsula. The sites vulnerable to deforestation and land use changes were chosen for the research. The study sites are depicted in Figure 1.

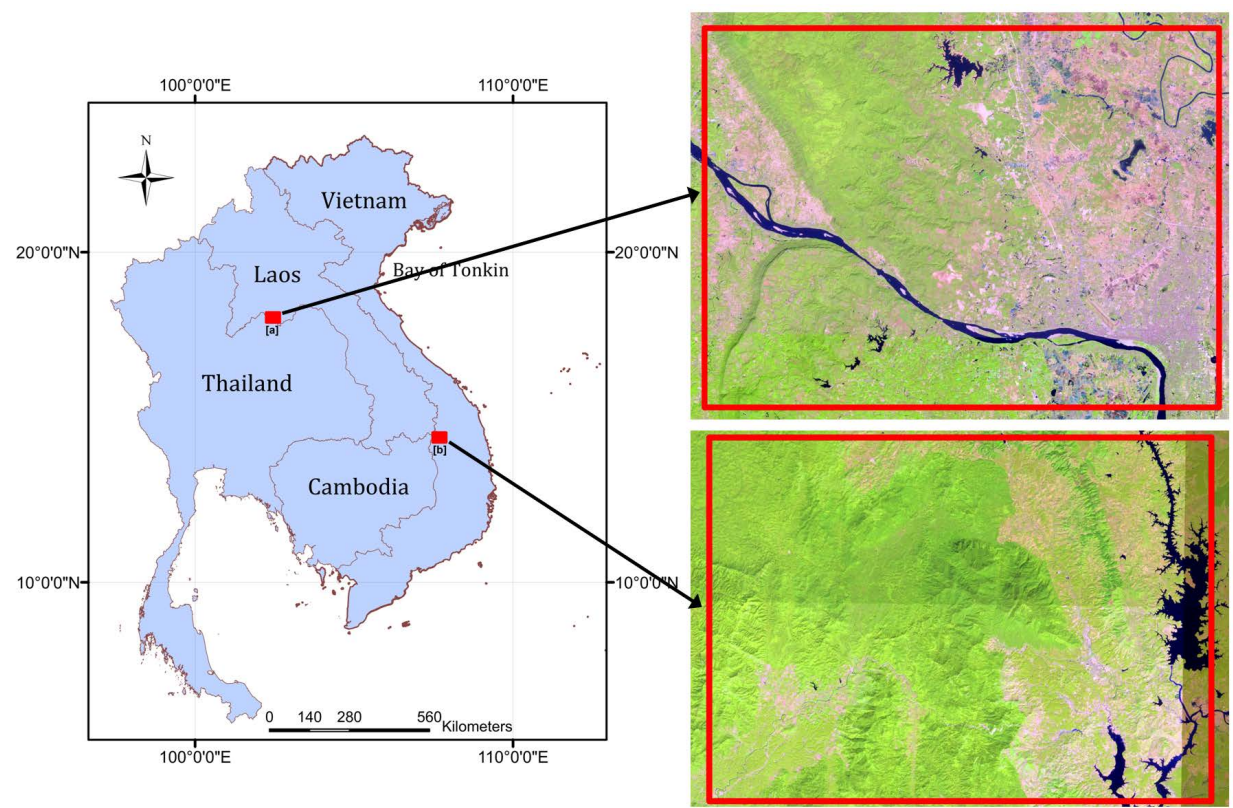

Figure 1. The study sites, Laos-Thailand [a], delineated (red polygon) over the false color composite Sentinel 2B image taken on 12 Dec 2019 and Vietnam [b], delineated (red polygon) over the false color composite Sentinel 2B image taken on 14 Nov 2018. 


\subsection{Generation of Composite Images}

We processed all Sentinel-1 Ground Range Detected (GRD) product scenes and Sentinel-2 Top-Of-Atmosphere (TOA) reflectance product scenes available over two study sites in 2018. Cloudy pixels in the Sentinel-2 scenes were masked out by using a separate quality assessment band available with the data. Sentinel-2 images with spatial resolutions varying from 10 to $20 \mathrm{~m}$ were resampled into 10 $\mathrm{m}$. Sentinel-1 scenes were processed for radiometric calibration and terrain correction. The Sentinel-1 mission provides C-band SAR data. We extracted VH polarization data, and resampled it into $10 \mathrm{~m}$ resolution to match with Sentinel-2 data. Using all the multi-temporal Sentinel-1 SAR and Sentinel-2 Optical images available over the study sites in the entire year of 2018, four composite images (BIC, FCC, EFCC, and WCC) were generated. The composite images are shown in Equations (1)-(4) in the following sections.

The BIC is a RGB (red, green, blue) color composite image made up of Normalized Difference Vegetation Index (NDVI), short wave infrared reflectance, and green reflectance, which were specially selected from the day of highest vegetation activity over an entire year (Sharma et al., 2016). The composition of the BIC is shown in Equation (1).

$$
\mathrm{BIC}=\left\{\begin{array}{l}
\operatorname{Red}(\mathrm{R})=\mathrm{Swir}_{\mathrm{NDVImax}} \\
\operatorname{Green}(\mathrm{G})=\mathrm{NDVI}_{\max } \\
\operatorname{Blue}(\mathrm{B})=\mathrm{Green}_{\text {NDVImax }}
\end{array}\right.
$$

In Equation (1), NDVI is calculated by normalizing the difference between the near infrared (Nir) and red (Red) reflectance (Rouse et al., 1974). The annual maximum NDVI $\left(\mathrm{NDVI}_{\max }\right)$ represents the highest vegetation activity period. The short wave infrared $\left(\mathrm{Swir}_{\mathrm{NDVImax}}\right)$ and green $\left(\mathrm{Green}_{\mathrm{NDVImax}}\right)$ reflectance from the day, when NDVI is maximum, are used to expose barren and water areas, respectively. The BIC was designed to be able to discriminate between vegetative (forests, crops, grasses) and non-vegetative (barren, urban, and water) areas.

Forest Cover Composite (FCC) was designed for the separate extraction and visualization of forest canopy in the assumption that annual mean values of the forested areas are usually lower than that of other non-forested areas (Sharma et al., 2018). The composition of the FCC is shown in Equation (2).

$$
\mathrm{FCC}=\left\{\begin{array}{l}
\operatorname{Red}(\mathrm{R})=\mathrm{Swir}_{\mathrm{NDVI} \text { max }} \\
\operatorname{Green}(\mathrm{G})=\mathrm{NDVI}_{\text {mean }} \\
\operatorname{Blue}(\mathrm{B})=\mathrm{Green}_{\mathrm{NDVI} \max }
\end{array}\right.
$$

Enhanced FCC (EFCC) was designed for enhanced extraction and visualization of the forested areas, the annual median backscattering intensity of the $\mathrm{VH}$ (Vertical-transmit horizontal-receive) polarization values $\left(\mathrm{VH}_{\text {median }}\right)$ obtained from Sentinel-1 mission. The Enhanced FCC (EFCC) as shown in Equation (3) was also proposed in a previous study (Sharma et al., 2018).

$$
\mathrm{EFCC}=\left\{\begin{array}{l}
\operatorname{Red}(\mathrm{R})=\mathrm{Swir}_{\mathrm{NDVImax}} \\
\operatorname{Green}(\mathrm{G})=\mathrm{NDVI}_{\text {mean }} \times \mathrm{VH}_{\text {median }} \\
\operatorname{Blue}(\mathrm{B})=\mathrm{Green}_{\mathrm{NDV} \text { Imax }}
\end{array}\right.
$$


Water Cover Composite (WCC) was designed for better extraction of surface water bodies in previous study (Sharma et al., 2015; Sharma et al., 2019). It is made up of annual minimum green $\left(\mathrm{Green}_{\min }\right)$ reflectance, annual minimum near infrared $\left(\mathrm{Nir}_{\min }\right)$ reflectance, and annual maximum Superfine Water Index $\left(\mathrm{SWI}_{\max }\right)$ values as the red $(\mathrm{R})$, green $(\mathrm{G})$, and blue (B) bands respectively. The composition of the WCC is shown in Equation (4).

$$
W C C=\left\{\begin{array}{l}
\operatorname{Red}(\mathrm{R})=\mathrm{Green}_{\text {min }} \\
\operatorname{Green}(\mathrm{G})=\mathrm{Nir}_{\text {min }} \\
\operatorname{Blue}(\mathrm{B})=\mathrm{SWI}_{\text {max }}
\end{array}\right.
$$

\subsection{Preparation of Ground Truth Data}

This research deals with the classification and mapping of four major land cover types, forest, crop, grass, and non-vegetation (water, barren, and built-up) present in the study sites. We prepared the ground truth data through visual interpretation procedure with reference to the Google Earth imagery. Altogether, 100 geo-location points, representing as large as $90 \times 90 \mathrm{~m}$ homogenous area, were prepared for each class for each site.

\subsection{Machine Learning and Mapping}

Three machine learning classifiers, k-Nearest Neighbors (KNN; Cover \& Hart, 1967; Altman, 1992), Support Vector Machines (SVM; Cortes \& Vapnik, 1995) and Random Forests (RF; Breiman, 2001) were employed to evaluate performance of the composite images (BIC, FCC, EFCC, and WCC) for the classification of land cover types. The performance of the composite images was evaluated by a 5 -fold cross-validation approach. Further details on the machine learning and cross-validation procedure have been described in previous study (Sharma et al., 2017). The accuracy metrics, overall accuracy and Kappa coefficient, calculated through the cross-validation approach were used for quantitative evaluation. The parameters of the classifier were optimized by repeated trial and error methods seeing the validation metrics. Land cover maps were also produced in each study site using the best-performed classifier.

\section{Results and Discussion}

\subsection{Cross-Validation Results}

Three machine learning classifiers-based validation results are shown in Figure 2 and Figure 3. The performance of the composite images varied slightly with study sites and classifiers used. In the Laos-Thailand site (Figure 2), composite images using RF classifier provided slightly better results (overall accuracy = 0.92 , Kappa coefficient $=0.89)$ than the KNN; whereas SVM performed less efficiently. However, in the Vietnam-Cambodia site (Figure 3), both the KNN and RF classifiers performed slightly better (overall accuracy $=0.90$, Kappa coefficient $=0.86$ ) than SVM. Nevertheless, we did not find substantial difference among 
the classifiers employed. Overall, the features obtained from four composite images showed promising results in all sites. Therefore, the composite images were confirmed effective for the classification of major land cover types.

\subsection{Land Cover Maps}

We employed the best performed classifier (Random Forests) for the production of land cover maps in each study site using the combination of composite images (BIC, FCC, EFCC, and WCC). The resulting land cover maps are shown in Figure 4.

Using the Random Forests algorithm with a combination of the four composite images (BIC, FCC, EFCC, and WCC), we can get land cover maps with very high accuracies. The accuracies of land cover maps for Laos-Thailand and Vietnam sites are up to 0.92, Kappa 0.89 and 0.9, Kappa 0.86, respectively.

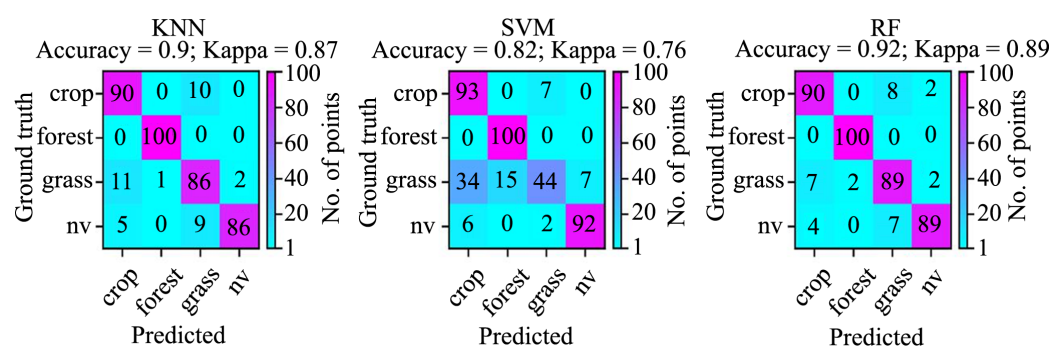

Figure 2. Performance of composite images for classification of land cover types in Laos-Thailand site using different classifiers.

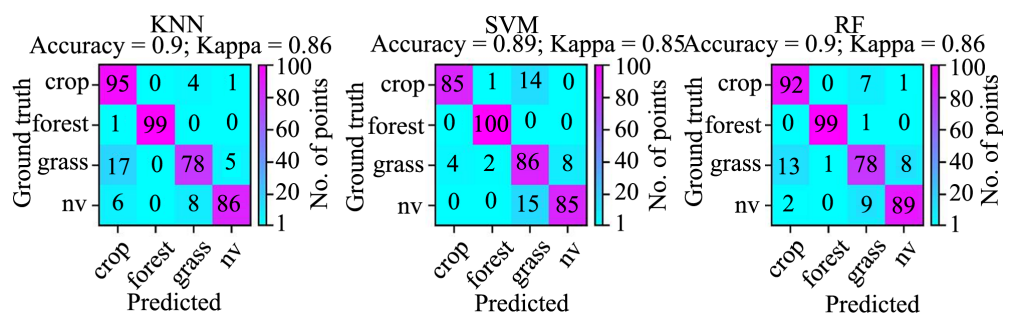

Figure 3. Performance of composite images for classification of land cover types in Vietnam-Cambodia site using different classifiers.

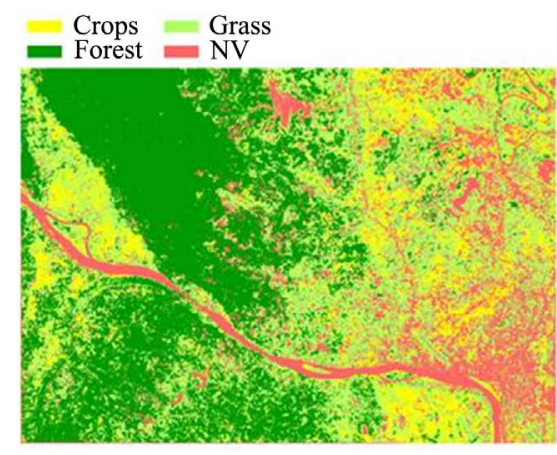

(a)

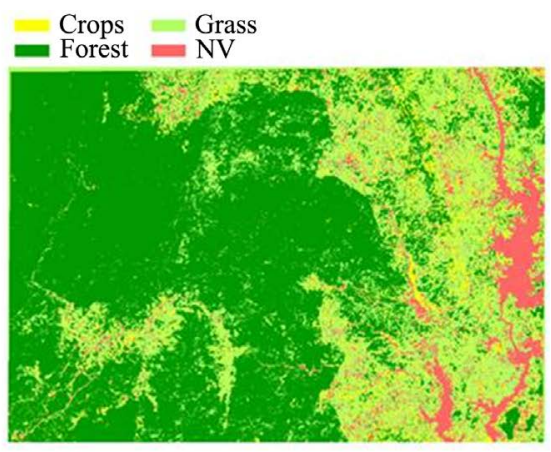

(b)

Figure 4. Land cover maps for Laos site (a) and Vietnam site (b) produced under the research. 


\section{Conclusion}

Image compositing techniques have evolved as an alternative approach for the retrieval of concise biophysical information from massive volumes of multi-temporal images from different sensors. In this research, we evaluated the performance of recently available composite images, such as BIC, FCC, EFCC, and WCC for the classification and mapping of land cover types in two study sites in the Indochinese peninsula. The composite images were designed for the extraction of individual land cover types; however the machine learning and validation approach employed in the research showed that the composite images are also efficient for the classification of major land cover types. The overall accuracies (Kappa coefficient) obtained from the combination of composite images were $0.92(0.89)$ and 0.90 (0.86) for Laos-Thailand, and Vietnam sites respectively. These results highlight effectiveness of the composite images for the classification and mapping of land cover types. The methodology presented in the research is expected to be useful for land cover monitoring in other regions as well. Further improvement of the classification accuracy by aggregating the results from different classifiers is recommended.

\section{Acknowledgements}

This research was funded by Vietnam Academy of Science and Technology (VAST) under project code KHCBTĐ.02/19-21 and Tay Nguyen Program 2016-2020 under project code TN18/T10. Sentinel-1 and Sentinel-2 mission satellite data were available from European Space Agency (ESA) Copernicus program.

\section{Conflicts of Interest}

The authors declare no conflicts of interest regarding the publication of this paper.

\section{References}

Altman, N. S. (1992). An Introduction to Kernel and Nearest-Neighbor Nonparametric Regression. The American Statistician, 46, 175-185. https://doi.org/10.1080/00031305.1992.10475879

Boyle, S. A., Kennedy, C. M., Torres, J., Colman, K., Pérez-Estigarribia, P. E., \& de la Sancha, N. U. (2014). High-Resolution Satellite Imagery Is an Important yet Underutilized Resource in Conservation Biology. PLoS ONE, 9, e86908.

https://doi.org/10.1371/journal.pone.0086908

Breiman, L. (2001). Random Forests. Machine Learning, 45, 5-32. https://doi.org/10.1023/A:1010933404324

Cortes, C., \& Vapnik, V. (1995). Support-Vector Networks. Machine Learning, 20, 273-297. https://doi.org/10.1007/BF00994018

Cover, T., \& Hart, P. (1967). Nearest Neighbor Pattern Classification. IEEE Transactions on Information Theory, 13, 21-27. https://doi.org/10.1109/TIT.1967.1053964

de Bruyn, M., Stelbrink, B., Morley, R. J., Hall, R., Carvalho, G. R., Cannon, C. H. et al. (2014). Borneo and Indochina Are Major Evolutionary Hotspots for Southeast Asian 
Biodiversity. Systematic Biology, 63, 879-901. https://doi.org/10.1093/sysbio/syu047

Dudgeon, D. (2000). Large-Scale Hydrological Changes in Tropical Asia: Prospects for Riverine Biodiversity: The Construction of Large Dams Will Have an Impact on the Biodiversity of Tropical Asian Rivers and Their Associated Wetlands. BioScience, 50, 793-806. https://doi.org/10.1641/0006-3568(2000)050[0793:LSHCIT]2.0.CO;2

Herold, M., See, L., Tsendbazar, N.-E., \& Fritz, S. (2016). Towards an Integrated Global Land Cover Monitoring and Mapping System. Remote Sensing, 8, 1036. https://doi.org/10.3390/rs8121036

Hoan, N. T., Liou, Y. A., Nguyen, K. A., Sharma, R. C., Tran, D. P., Liou, C. L., \& Cham, D. D. (2018). Assessing the Effects of Land-Use Types in Surface Urban Heat Islands for Developing Comfortable Living in Hanoi City. Remote Sensing, 10, 1965. https://doi.org/10.3390/rs10121965

Hoan, N. T., Tateishi, R., Alsaaideh, B., Ngigi, T., Alimuddin, I., \& Johnson, B. (2013). Tropical Forest Mapping Using a Combination of Optical and Microwave Data of ALOS. International Journal of Remote Sensing, 34, 139-153. https://doi.org/10.1080/01431161.2012.709329

Kanae, S., Oki, T., \& Musiake, K. (2001). Impact of Deforestation on Regional Precipitation over the Indochina Peninsula. Journal of Hydrometeorology, 2, 51-70. https://doi.org/10.1175/1525-7541(2001)002<0051:IODORP>2.0.CO;2

Keenan, R. J., Reams, G. A., Achard, F., de Freitas, J. V., Grainger, A., \& Lindquist, E. (2015). Dynamics of Global Forest Area: Results from the FAO Global Forest Resources Assessment 2015. Forest Ecology and Management, 352, 9-20. https://doi.org/10.1016/j.foreco.2015.06.014

Kerr, J. T., \& Ostrovsky, M. (2003). From Space to Species: Ecological Applications for Remote Sensing. Trends in Ecology \& Evolution, 18, 299-305. https://doi.org/10.1016/S0169-5347(03)00071-5

Keyes, C. F. (1994). The Golden Peninsula: Culture and Adaptation in Mainland Southeast Asia. Honolulu, HI: University of Hawaii Press.

Lawrence, D., \& Vandecar, K. (2015). Effects of Tropical Deforestation on Climate and Agriculture. Nature Climate Change, 5, 27-36. https://doi.org/10.1038/nclimate2430

Malenovský, Z., Rott, H., Cihlar, J., Schaepman, M. E., García-Santos, G., Fernandes, R., \& Berger, M. (2012). Sentinels for Science: Potential of Sentinel-1, -2, and -3 Missions for Scientific Observations of Ocean, Cryosphere, and Land. Remote Sensing of Environment, 120, 91-101. https://doi.org/10.1016/j.rse.2011.09.026

Miettinen, J., Stibig, H.-J., \& Achard, F. (2014). Remote Sensing of Forest Degradation in Southeast Asia-Aiming for a Regional View through 5 - 30 m Satellite Data. Global Ecology and Conservation, 2, 24-36. https://doi.org/10.1016/j.gecco.2014.07.007

Mulatu, K., Mora, B., Kooistra, L., \& Herold, M. (2017). Biodiversity Monitoring in Changing Tropical Forests: A Review of Approaches and New Opportunities. Remote Sensing, 9, 1059. https://doi.org/10.3390/rs9101059

Rouse, J., Haas, R., Schell, J., \& Deering, D. (1974). Monitoring Vegetation Systems in the Great Plains with ERTS. Boston, MA: ScienceOpen, Inc.

Roy, D. P., Wulder, M. A., Loveland, T. R., Woodcock, C. E., Allen, R. G., Anderson, M. C. et al. (2014). Landsat-8: Science and Product Vision for Terrestrial Global Change Research. Remote Sensing of Environment, 145, 154-172. https://doi.org/10.1016/j.rse.2014.02.001

Sen, O. L., Wang, Y., \& Wang, B. (2004). Impact of Indochina Deforestation on the East Asian Summer Monsoon. Journal of Climate, 17, 1366-1380. 
https://doi.org/10.1175/1520-0442(2004)017<1366:IOIDOT>2.0.CO;2

Sharma, R. C., Hara, K., \& Hirayama, H. (2017). A Machine Learning and Cross-Validation Approach for the Discrimination of Vegetation Physiognomic Types Using Satellite Based Multispectral and Multitemporal Data. Scientifica, 2017, Article ID: 9806479. https://doi.org/10.1155/2017/9806479

Sharma, R. C., Nguyen, H. T., Gharechelou, S., Bai, X., Nguyen, L. V., \& Tateishi, R. (2019). Spectral Features for the Detection of Land Cover Changes. Journal of Geoscience and Environment Protection, 7, 81-93. https://doi.org/10.4236/gep.2019.75009

Sharma, R., Hara, K., \& Tateishi, R. (2018). Developing Forest Cover Composites through a Combination of Landsat-8 Optical and Sentinel-1 SAR Data for the Visualization and Extraction of Forested Areas. Journal of Imaging, 4, 105. https://doi.org/10.3390/jimaging4090105

Sharma, R., Tateishi, R., \& Hara, K. (2016). A Biophysical Image Compositing Technique for the Global-Scale Extraction and Mapping of Barren Lands. ISPRS International Journal of Geo-Information, 5, 225. https://doi.org/10.3390/ijgi5120225

Sharma, R., Tateishi, R., Hara, K., \& Nguyen, L. (2015). Developing Superfine Water Index (SWI) for Global Water Cover Mapping Using MODIS Data. Remote Sensing, 7, 13807-13841. https://doi.org/10.3390/rs71013807

Stibig, H.-J., Achard, F., Carboni, S., Raši, R., \& Miettinen, J. (2014). Change in Tropical Forest Cover of Southeast Asia from 1990 to 2010. Biogeosciences, 11, 247-258. https://doi.org/10.5194/bg-11-247-2014

Wang, K., Franklin, S. E., Guo, X., \& Cattet, M. (2010). Remote Sensing of Ecology, Biodiversity and Conservation: A Review from the Perspective of Remote Sensing Specialists. Sensors, 10, 9647-9667. https://doi.org/10.3390/s101109647 